\title{
Theory is Not Enough! Experiential and Project-Based Approaches to Teaching International Social Work
}

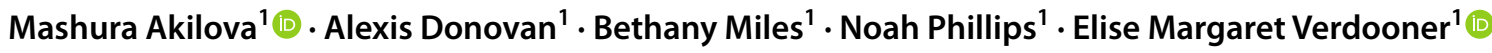

Accepted: 8 February 2021 / Published online: 10 April 2021

(C) The Author(s), under exclusive licence to Springer Nature Switzerland AG part of Springer Nature 2021

\begin{abstract}
In the increasingly interconnected and interdependent world, social work education requires a more global approach to graduating better-prepared practitioners. Teaching international social work only based on classroom and second-hand experiences do not expose students to the realities, opportunities, and challenges of work in the field. While there are longer-term volunteering or internship-based field immersion programs, shorter-term collaborations mixing in-class and field learning in international social work education are practiced less. Experiential and project-based courses provide students with opportunities to learn from practitioners, while also providing the reciprocal benefit of time, human, and academic resources of their institution to their partner agencies. This model of education provides aspiring practitioners skills in and models of international collaboration, reducing the risks that learning takes place only at the expense of host communities. The key takeaways of this approach from the experience of students in the course Social Work Practice with Displaced Persons are discussed in this paper. The course provides structured instruction and exposes students to experts in the field of humanitarian response through collaborative projects, field visits, and seminars with practitioners. The analysis of the qualitative data from students' course reflections shed light on several broad themes on the value of experiential project-based education and the impact of field immersion on the development of essential skills necessary for social workers entering the field of humanitarian response and practice with displaced persons. A case for mainstreaming project-based learning in international social work education to better prepare informed, effective, and efficient practitioners and leaders is presented.
\end{abstract}

Keywords International social work education - Social work with displaced persons and refugees - Experiential education · Project-based education

In our increasingly diverse society and globalized world, social workers must understand how culture, history, language, traditions, economics, and (geo)politics impact the development, study, and practice of the profession with diverse groups of people (Sewpaul \& Jones, 2005). As

Mashura Akilova

ma2918@ columbia.edu

Alexis Donovan

akd2142@columbia.edu

Bethany Miles

bjm2183@columbia.edu

Noah Phillips

sp3471@columbia.edu

Elise Margaret Verdooner

emv2140@columbia.edu

1 Columbia University School of Social Work, New York, NY, USA events worldwide ripple into areas of domestic social work practice, it becomes clear that curricula focused exclusively on domestic issues or theoretical concepts are inadequate in preparing social work students for international practice. The calls to internationalize social work education in Western countries (Carata \& Sanchez, 2002; Sewpaul \& Jones, 2005) have never been more relevant. The impacts of climate change, human mobility, and global epidemics are clear evidence of the need to educate and prepare social work professionals with cultural sensitivity, worldly awareness, and field experience. The Education Policy and Accreditation Standards developed by the U.S. Council on Social Work Education (CSWE) requires nine competencies, one of which assesses students' ability to advance human rights and social, economic, and environmental justice from local and global perspectives (CSWE, 2015). When properly implemented, social work students should understand the "global interconnections of oppression and human rights 
violations, and are knowledgeable about theories of human need and social justice and strategies to promote social and economic justice and human rights," and are able to implement strategies to undo oppressive practices (CSWE, 2015 p. 7). This requires the provision of appropriate tools and skills to students who will work with populations of complex needs and strengths, such as survivors of torture, refugees, or migrants. Understanding global systems of oppression, which may be similar and different from issues students learn through their own experiences, is better apprehended through personal engagement with those systems or connections to persons who have been impacted by them. Therefore, the inclusion of international experiential social work courses into Bachelor of Social Work (BSW) and Master of Social Work (MSW) curricula is essential in graduating holistically prepared social work and human rights practitioners.

The Commission on Global Social Work Education defines international social work as "a discrete field of practice within social work that seeks to improve the social and material well-being of people everywhere" (Estes, 2010, p. 5). More than simply the expansion of social work across regional borders, international social work seeks to address social problems stemming from geopolitical forces, such as forced displacement, economic development, and human trafficking (Estes, 2010; Healy, 2008). Social work practitioners should be engaging diverse social actors such as practitioners, universities, and local governments among others, which can lead to the easier promotion of global solidarity, democracy, and a greater possibility to prevent conflicts (Ahmadi, 2003). International and interdisciplinary collaboration is necessary to address the complexity of the social problems associated with globalization (Kjørstad \& Wolmesjö, 2016). By learning about professional practice in the context of other countries' social, cultural, economic, and political frameworks, social workers can be better prepared for the realities and challenges of global and domestic practice. It is especially important to incorporate this element of professional exchange into the education of social workers aiming to practice internationally. Therefore, the global standards of education should align with local, national, regional, and international developmental needs and priorities (Sewpaul \& Jones, 2005).

Practitioners and scholars alike agree that international social work cannot be merely taught through traditional methods of learning. They advocate for critically reflective and reverse mission frameworks, which are designed to challenge traditional approaches to teaching and learning, Eurocentrism, and, by extension, oppressive neo-Colonialism (Caragata \& Sanchez, 2002; Das \& Anand, 2014; Abram et al., 2005). The knowledge should not only transfer from the Global
North to the Global South but should rather be produced in a collaborative approach. Scholars call for a concerted effort to learn from the Global South experiences, where students from universities in the Western Hemisphere can challenge their own biases and deepen their understanding of the pertinent power dynamics and value of knowledge from diverse contexts. This is important for any social worker practicing globally, and especially crucial in practice with marginalized populations, such as displaced persons.

The collaborative critically reflective framework is particularly important in humanitarian emergency contexts where beneficiaries are disempowered on multiple levels. Practitioners, policymakers, and administrators holding access to resources should be aware of the power imbalance and use approaches that restore some power to beneficiaries. Practitioners entering this field of practice must be trained to understand these nuances to protect displaced persons from harm, including harm caused unintentionally or through a waste of resources on ineffective programs. Knowing the approaches that work can mean the difference between life and death, especially in emergency settings. Furthermore, while on-the-job training in emergency settings is important, the potential impact from an inexperienced practitioner or administrator is high. Culturally relevant, locality-specific approaches in emergency response and management can empower affected people and reduce the risks of harm (Dominelli, 2014).

\section{International Social Work Education Approaches: Project-based Learning}

A number of different methods for teaching international social work have been identified and tested in the literature. Mapp and Gatenio Gabel (2019) surveyed BSW and MSW programs in 47 states, DC, and three US territories. They found that a combination of specialized talks and events on international social work and infusion of international content into existing courses were the most common methods used by the programs in the study sample. The short-term study abroad courses (offered by $75 \%$ of the sample) and international field placements (offered by $50 \%$ of the sample) provide students more contextual experience and knowledge but are less commonly used as an approach to international social work education. Regardless of the method of international social work education used, the survey showed that only two-thirds of the programs aim to teach students to "develop social work interventions based on knowledge of global social issues"(Mapp \& Gatenio Gabel, 2019 p. 245). The majority of the programs focused on simpler objectives that aim to teach students to understand and discuss global social issues and how they affect social work, while a third of the respondents do 
not aim at providing the knowledge of international social work to their students.

The ubiquity of required field engagement in domestic social work education implies agreement on the utility of interactive and experiential models of teaching to facilitate practical knowledge acquisition, which can be applied to the subfield of international social work (Boyle et al., 1999; Greenfield et al., 2012; Kjorstad \& Wolmesjo, 2016; Moorhead et al., 2013; Zubaroglu \& Popescu, 2016). Mapp and Gatenio Gabel (2019) found that the administrative burden to host institutions, the challenges of placing in non-English speaking countries, or the faculty connections could make international field placements more challenging. Given the preference to, and comparative ease of, administering short-term study abroad classes, they may offer a more manageable immersive and firsthand experience for students if well organized, while not perpetuating oppressive practices, such as voluntourism. McGloin and Georgeou (2016) warn that voluntourism, run by private organizations appealing to students longing to "make a difference" or gain experience in international development context, reinforces colonialism. Volunteers do not have meaningful opportunities to engage with the communities and understand the causes of the problems they come to "fix." As Lough (2014) describes, student volunteers using the experience as a means to learn or gain experience, when left without much educational guidance or ability to reflect in depth about what they learn, can contribute further to "white-saviorism," (Cole, 2012) a practice that often results in harm. Mapp and Rice (2018) offer a "rights-based" approach to study abroad models, which is rooted in human dignity, nondiscrimination, participation, transparency, and accountability. Shifting from providing services or charitable donations, a rights-based approach encourages students to recognize the work they are doing as facilitating beneficiaries' access to fundamental human rights by ensuring transparency and collaborative decisionmaking processes.

Beyond social work, other fields of practice have utilized a project-based model to teach international content and skills (Schachter \& Schwartz, 2009; Reinfenberg \& Long, 2017). Danford (2004) discussed project-based learning in international business education in which students collaborate on real projects with corporations, which enhances student learning by equipping them with the skills necessary to effectively engage in real-life business situations. At the same time, partners benefit from the costeffective labor provided by students as well as the expertise of the faculty and institution involved. In the field of nursing, Brown (2017) described a 2-week service-learning trip to Belize, which allowed students to deepen their nursing competencies and identify barriers to treatment that were specific to the global context, such as privacy concerns during treatment or access to clean water. A study of projectbased learning that explored the impact of collaboration between Australian occupational therapy students and community health workers at non-government organizations in India and Vietnam discussed how this experience was a critical component in developing students' sense of global citizenship, compelling them to practice with intercultural sensitivity (Fortune et al., 2019).

In the field of international social work, a project-based model such as the ones described by Danford (2004) and Brown (2017) is seldom used. A systematic review of 65 articles by Mercer-Mapstone and colleagues (2017) found that the majority (92\%) of partnerships in projectbased learning experiences occurred between students and academic staff, while only $8 \%$ of partnerships occurred between students and external stakeholders. MercerMapstone et al. (2017) discussed the benefits of external partnerships for student learning and called for student project-based learning practices that are not limited to traditional models of teaching and extend beyond the students' home countries. Thus, the preparation of social workers aiming to practice internationally should include both theoretical components, which will provide knowledge and skills, as well as practice elements and opportunity to apply theory to practice. Experiential learning provides such opportunity by allowing learners to acquire knowledge from their own experiences in the environment by testing and adjusting this knowledge according to changing conditions (Kolb \& Kolb, 2012). Merging theoretical and practical approaches is especially important for fields of social work practice such as humanitarian emergencies that require immediate immersion without much opportunity for on-thejob training post-graduation. As of 2021, the majority of the seventy million refugees, asylum seekers, and internally displaced persons are hosted in the Global South (UNHCR, 2021), in countries such as Jordan, Turkey, Bangladesh, and Uganda. Therefore, it is essential to prepare emerging international social workers in the field by offering opportunities to engage in structured and supervised international social work projects while they are students. Practice in the resource-rich countries where refugees are resettled does not provide an immersive experience that would prepare future practitioners to work in the context of the Global South.

A model that combines theoretical, practical and experiential approaches of training social workers in the field of forced displacement has been tested in an MSW program. The key takeaways of this model of international social work training are presented in this paper. This education model combines structured teaching of the subject with exposure of students to experts in the field through collaborative 
projects, field visits, and seminars with practitioners. To counter voluntourism practices and extractive learning benefits for students from the Global North, this education model also tests a collaborative approach to learning with each party mutually benefitting from the engagement. Rather than a group of students coming to a community to take and learn from them, they also give back responsibly using the resources they have, including time, academic, and human resources in their access and under the guidance of faculty mentors.

\section{Course Design Description}

\section{Student Selection and Sample}

Social Work Practice with Displaced Persons, designed as a 14-week full-semester course in an MSW program, was taught during the spring semesters of 2018, 2019, and 2020. Students were selected based on an application system in the fall semester prior to the course. Students with an interest in working with displaced persons and those in their final year of the program were prioritized. Other factors that were considered included students' pre-existing skills, preparedness to collaborate on projects with agencies in Jordan (2018-19) or Turkey (2020), and diversity in methods and fields of practice. Given the limited space, priority was given to students who would benefit the most from the course: those who needed the skills and knowledge for their practice with displaced persons or those who wanted to gain skills in international social work practice but had not had the opportunity to do so. For the 2019-2020 courses, the skills set (i.e., program evaluation, statistical analysis) that would be useful for the partner agencies was also a factor in selecting students.

The course was limited to 15-20 students to keep the group closely connected, facilitate meetings in the field, and enable effective project supervision. Over the course of 3 years, nearly 200 students applied, while 56 students were selected and completed the course. Two-thirds of the accepted students were in their final semester, while the remaining one-third were in the first year of their MSW program. Students' field of practice had approximately equal share of students in clinical, policy, and advanced generalist practice. There were only 3 students in the social enterprise administration field of practice over 3 years. The overwhelming majority of students (about $60 \%$ ) represented International Social Welfare and Practice with Immigrants and Refugees specialization. The remaining students specialized in Health and Mental Health (about 20\%), Contemporary Social Issues (15\%), and Children and Families $(5 \%)$. About half of the students had some international study/ work/volunteering experience, and the remaining students' international experience came from travel. Three students had zero international experience.

\section{Course Structure}

The course consisted of three distinct parts: pre-trip planning, including introducing the selected students to their team and partner agencies at the end of the fall semester (prior to the scheduled class) and 8 weeks of theoretical in-class preparation during the spring semester (hybrid: on-campus and online); field work, including the 10-day trip to Jordan; and post-trip in-class meetings synthesizing knowledge gained and completing project activities and final products. The field work (including the trip to Turkey) in Spring 2020 was cancelled due to COVID-19 travel limitations.

The course content aimed to prepare social work students planning careers in humanitarian or other settings to practice with refugees, asylum seekers, and internally displaced persons. The course was organized to develop students' capacities and knowledge about the global frameworks of practice, including history of response to the needs of displaced persons; major stakeholders in the field; policies and legal frameworks guiding humanitarian response practices; and areas of practice with displaced persons.

\section{Pre-trip Course and Preparation}

The course focused on host-country experiences to understand how global and local factors interact in the implementation of humanitarian policies. Historical context of the country's response to major groups of refugees was studied. The curriculum provided a review of the country's various policies and agreements with the international community in regards to the frameworks of practice as well as the country's political, social, cultural, economic, and human rights context to fully understand the challenges faced by host countries. Humanitarian and social work approaches in various sectors of response, such as livelihoods, shelter and housing, camp and urban practices with refugees, health and mental healthcare, education and child welfare, employment, host country integration, human rights, discrimination, trafficking and smuggling, sexual and gender-based violence, child labor and child marriages among many others, were discussed during the weeks prior to the trip.

Along with the theoretical training that students received in the first 8 weeks of the semester, they worked on projects with partner agencies in the field. Prior to the beginning of the course, several partnerships with agencies expressing interest in collaboration with the class had been secured. The projects were developed based on the needs of organizations and later finalized once the students were assigned to each project. In the second and third iteration of the course, this partnership became the central focus of the class, while the first course offered it on voluntary basis, with a third of the 
class opting-in. Students began engaging with the agencies at the end of the fall semester prior to the beginning of the class, so they had time to start necessary preparations and acquire ethical review board approvals for data collection for research studies. This gave the groups about 6 months (instead of four) from start to the end of the project.

The projects were selected carefully by the instructor in collaboration with partner agencies so they would be impactful, while avoiding perpetuation of the "white-savior complex." Agencies were provided with student bios and their areas of expertise in order to align agency needs with student abilities. There were extensive discussions on students' roles as learners, their positionality, and ethical and cultural guidelines for working with vulnerable communities. Projects that were implemented over 3 years of the class existence in Jordan and Turkey included research studies, program evaluation, process evaluation, and review of best practices with the aim to aid the design of psychosocial support programs for refugees. Overall, nine collaborative projects have been established with six having been completed. The three incomplete projects (in Turkey) were halted due to inability to conduct fieldwork in the midst of the COVID-19 pandemic.

\section{The Fieldwork}

The 10-day trip to the country of focus was a critical component of the experiential education in this course. The purpose of the trip encompassed (1) learning from experts in the field by creating opportunities that match theoretical knowledge in class to reality through observations, meetings, and implementation of the project activities; (2) witnessing the impact of policies and services on affected people firsthand; and (3) understanding the complexities of social work practice within humanitarian settings.

There was a difference in the structure of the trip in the first and the following course offerings. The trip in 2018 mainly focused on scheduled field visits to learn from the experiences of various agencies providing and advocating for services for refugees in Jordan. The group of students who volunteered to collaborate with the agency implemented the activities of the project during their time free from these field visits. The central focus of the subsequent fieldtrips in 2019 and 2020 related to implementation of the studentagency projects. Elements of the first field visit to agencies were transitioned into seminar-type discussions with practitioners organized to take place every morning during trip for two hours. These meetings offered opportunity to engage with a wide range of international and local stakeholders involved in various levels of response, including policy and administration (Ministries, UNHCR, UNRWA); humanitarian response clusters and working groups; community-based organizations; and local and international agencies providing health, mental healthcare, youth empowerment and programming, education, protection, shelter and livelihoods, and work support among others. The remainder of the day was organized to be spent in student partner agencies, collecting the necessary data and/ or visiting programs, aspects of which students studied.

\section{Post-trip Course Reflections and Project Finalization}

The remaining 6 weeks of the semester after return from the trip focused on debriefing, reflection, and application of what they had learned to their current and future practice contexts. Students used this time for data analysis and write-up of their project final products. Groups met weekly to work on data analysis, conduct agency checkins, and write up and presentation of final reports. The class final project results were presented at a school-wide event.

\section{Methodology}

This paper presents the outcome of an observational study of three cohorts of the Social Work Practice with Refugees and Displaced Persons course taught in spring 2018, 2019, and 2020. Student application essays, course reflection assignments, and project feedback were used to evaluate students' educational and project experiences.

Students' consent for using the materials has been secured, and data were anonymized before analyses. The qualitative data was manually coded and analyzed. The codebook was developed based on the initial coding of a random sample of eight student reflections and application essays (two per researcher) by a team of 4 authors. The codes were then discussed and combined into one codebook that was used to code the remaining sample of 48 participants. An effort was made to utilize codes that are applicable to all class cohorts, despite the differences in class structure. The sample for the first cohort includes 16 students, while the second- and third-year sample includes 20 students each, totaling 56 people across all cohorts. The analysis of codes focused on vertical and horizontal variation across the total sample of student data, as well as the three cohorts of students. The codes were then combined into themes that emerged from the reflections. The quotes that were used in the paper have been selected to highlight and provide context for each of the discussed themes. They represent all three cohorts, while the trip-related themes are based only on 2018-2019 cohort samples.

Themes in the post-course reflections were also compared with the initial goals for taking the class listed in the applications. The reflection paper data 
discussed various aspects of students' course, trip, and project experience and provided insights to implications for students' practice. The data analysis also focused on learning about various components of the course structure and how they contribute to students' learning and experiences.

\section{Findings}

Review of the students' application essays showed that most of the students were motivated to take the class to gain experience working in humanitarian emergency response, to broaden their perspectives on working with refugees internationally, and to have opportunities to learn about international social work in the context of local practice. The analysis of students' reflection papers highlighted several broad themes on the value of experiential vs. traditional courses; anti-oppressive lens to practice; and cultural humility necessary for social workers entering the field of humanitarian response, international social welfare in general or domestic social work practice with displaced persons, which will be further explored in this section. Comparison between the cohorts where the structure of the fieldtrip differed highlighted the value of project-based learning.

\section{Value of Experiential Education}

According to students' course assessments, one of the most noteworthy aspects of the Social Work Practice with Displaced Persons course was the distinct learning approach that is offered in contrast to other courses in the social work curriculum. Students described the opportunity to learn from the experience of other countries responding to the needs of displaced people as a critical experience. Many discussed the unique opportunity to triangulate their learning from multiple sources of information. The pre-trip preparations in the form of course discussions based on literature, guest presenters, and project tasks provided students with the ability to engage meaningfully while in the country.

For me, there was a real movement from the intellectualization of all of the reports, responses, statistics, treaties, compacts, etc. regarding refugees to the humanization and personification of the issues when brought to life by the seminar presenters and those who have lived experiences and direct relationships with all that we have been studying and exploring from afar.
At the same time, learning from the expertise of frontline practitioners on the nuts and bolts of coordinating humanitarian work, observing these practices in real time was an invaluable experience that is hard to substitute in theoretically focused classrooms. For instance, some students noted how the requirements of the Jordan Compact may have sounded too abstract until they saw its impact on program implementation:

Prior to the trip, we learned that organizations in Jordan that serve refugees must ensure that at least $30 \%$ of their clients are Jordanians. It was interesting to learn that [agency] fulfills this requirement by conducting trauma training that targets Jordanians in the community and at universities.

Students appreciated the holistic approach to learning about the field of emergency and long-term humanitarian response, allowing for the comparison of global frameworks and their USA-based experience to the Jordanian context. The ability to see the application of these frameworks in the field fostered students' critical thinking by highlighting realities that were otherwise "underscored in a classroom environment":

The discrepancy between advocates of the Jordan Compact in academic circles, and the realities presented by actors on the ground speaks to a more fundamental gap of implementation, pervasive across the humanitarian sector, between knowledge, policy, and guidance on one hand, and context-specific implementation on the other.

This experience allowed students to understand the impact of the response to the needs of refugees not only from the perspectives of displaced persons, but also their host communities:

Mostly, this trip highlighted to me how much more there is to learn, and the complexities in which refugees must navigate through society in host countries. Almost every [native] person we met could recount the history of Jordan and its involvement with displaced people, down to the dates and waves of migrations. This is a reality, not just for refugees, but for the host community as well.

In reflecting on their learning from field visits, students questioned their previous perceptions and assumptions: “'Is this a camp? Are these people all refugees?' Until I observed people and how they lived, I could not imagine what it means for people to live in another country for more than sixty years as refugees." As noted by a student visiting some of the field sites as part of their project, "the literature [...] depicted women to be weak and struggling greatly in this particular field [food processing business]. 
However, when we visited the field sites, I witnessed the power and strength of women in [agency] and how resilient and entrepreneurial they all are." In reflecting on their role in the project partnership with a community organization in Zaatari camp, a student observed:

[I] found myself also having to re-examine my own experiences working with youth programs to determine how realistic and possible the details that were so integral are in the reality of limited budget, space, and time, and really examining what it means to participate in a program in a 'protracted' environment.

Students, across cohorts, discussed the importance of human connections facilitated through experiential learning, highlighting how their ability to connect in person with a multitude of stakeholders, beneficiaries, and locals added to their experience, which was one of the most commented upon takeaways. One student reflected, "I was floored by the honesty and willingness of so many people to engage in open dialogue with us regarding the work that they do and the challenges of aid work." This connectedness helped students "explore differences mutually and respectfully" and "navigate [the] role of a social worker in this field and humanitarian work with refugees." Also, importantly, "the literature often focuses on the differences between people, society, religion, etc. but in person in Jordan I found that our relationships (working/interviewing/service utilization) began with a focus on similarities and connections rather than what separated us."

The depth of impact of various contextual factors affecting the practice was understood better through an immersive experience. During one of the visits to the health clinic in the camp for Palestinian refugees, doctors discussed the potential closure of the clinic due to the Trump Administration's funding cuts to UNWRA in 2018; this clinic provides for all medical needs of the refugees. Students spent a significant amount of time reflecting on their own government's role in creating challenges in the field: "I have heard the term "no money no mission' many times [...] it has never been so real as during the UNRWA meeting." Other students discussed how interacting with practitioners made them think about their roles as decision-makers prioritizing some services over others, not based on the needs or best evidence, but based on available funding: "I think it is easy for me to say that engaging men [in GBV response] is widely considered best practice in women's empowerment, but in humanitarian settings, many organizations don't have the luxury, funding, or resources for engaging in such programming."

\section{Field Trip Structure: Agency Field Visits vs. Project-based Fieldwork}

\section{Agency Field Visits}

The structure of the field visits differed for each cohort. The first trip immersed students in the field by providing them the opportunity to observe the work as it happened on multiple levels of humanitarian response. Students reported gaining comprehensive knowledge around the role of social work practice in refugee crisis response through meetings with Jordan-based agencies in the field. Students learned through discussions with experts; visits of the cluster meetings in various sectors of humanitarian response, such as education or mental health; and by observing some of the programs in progress. The overall course feedback discussed the value and depth of learning, with the majority of students also cognizant of the "one-sidedness" of the benefits of the trip. While students gained much, learning from the expertise and time of the professionals on the frontlines, they, as a group, did not offer much in return: "I do not want to be another course that simply learns for the sake of my own learning and yet fail to do something about it [the refugee crisis]." Other students discussed their discomfort during their field visits, "I felt we were doing 'refugee tourism' to some extent. Working hard to explore ways of collaboration with these organizations in the future should be our responsibility."

Even though the course ensured the visits did not include encounters with refugees, focusing mostly on meeting with practitioners, students voiced a resounding desire to engage more meaningfully with the service providers, a practice that could facilitate a mutual benefit for future courses. They were keenly aware and committed to reshaping some of the existing issues in international development, such as voluntourism. These sentiments were further supported by observing the impact of the optional collaborative project that involved six of the students from the first cohort. Students felt gratification learning that their partner agency gained recognition by the UN and consequently got more access to funding as a result of the program evaluation report produced by the student group. As one student reflected, "knowing that our work with [the NGO] went beyond our own personal and professional interest, and actually resulted in a tangible positive result for the organization, made our hard work all the more worth it." Based on student feedback, reciprocal learning opportunities were explored through "longer-term projects and collaborations between schools of social work from the US and Jordan that fosters an environment of support and equity [that] can be the future goal for this in ensuring its productivity as well as sustainability." 


\section{Project-based Fieldwork}

While project-based learning emerged as a valuable mode of educating students of all three cohorts, it became the central focus for 2019 and 2020 cohorts. By partnering with agencies on the ground, students had greater opportunities to learn in more depth by applying the concepts they learned in class and observing them implemented in practice. Students demonstrated a deep understanding of the complexity of humanitarian response and the value of collaboration with local partners that was facilitated by their projects: "being placed in a group project in collaboration with an international agency provides students an exceptional experience to [learn] about international development directly from the field and from major international organizations."

Students considered projects as a valuable and central part of their learning experience. The pre-trip coursework, project planning, and trip observations and reflections were enhanced through their engagement in the day-to-day activities of the local agencies.

It was rewarding to arrive with a comprehensive understanding of Jordan's response to the refugee crisis, but it was even more rewarding to have said understanding enhanced through guest speakers and my group's work with [agency] and its beneficiaries. I have enjoyed the experience and learned a lot from our partners in Turkey. The project met the expectations set prior to the beginning of the semester, though I still felt a bit unprepared to carry out a research project of this magnitude. Most importantly, I learned that I really do want to work in the international field and contribute to the best-practice knowledge.

While reflecting on the trip during the class, one student raised an idea about the potential service trip as opposed to the project-partnership model. The rest of the students showed strong opposition, specifically relating it to what is wrong with the system of voluntourism in international development:

I know there was much conversation surrounding service work for future trips. I would like to put in my vote against this idea. [...] Volunteering can feel good, but often does not have impact at which point it becomes about the volunteers, not the ones that the volunteers are there to serve.

\section{Learning Through an Anti-oppressive Lens and Practicing Cultural Humility}

One of the most important lessons that students learned related to various ways that social work can be practiced in different contexts, which does not always have to fit the definition of Eurocentric professional models of practice. Although the actual social work profession in Jordan only focuses on casework, many students observed that agencies in the field working with refugees are already practicing social work, regardless of the absence of professional training, by promoting cultural humility, human rights, person-first, social justice, and strength-based values. The quote "it does not have to be called social work for it to be social work" accurately summarizes students' reactions observing practitioners in Jordan who were not professionally trained in social work. They also discussed "how many organizations [working with refugees] seemed to be embodying social work principles, which wasn't necessarily what we expected," and emphasized how much there is to learn from how the profession is practiced in Jordan.

Among the Syrian volunteers, there seemed to be a partnership rather than a clearly defined top-down organizational structure. This was particularly striking to me as an organizational model of community work and engagement, which seemed to enhance the efficacy of the goals of the program.

The group constantly reflected on their positionality and privilege coming from the Global North, in relations to the people they served, as well as the practitioners with whom they collaborated:

Part of me felt uncomfortable having three social workers who are doing hard, amazing work look to us and ask for recommendations. I felt that I'm not doing their work every day, they know this work inside and out, they know what is missing, and they know what needs to be improved. I understand they are looking for outside opinions when collaborating with [the social work school] but part of me felt, "who am I to give them advice?"

In their fieldwork, students had an opportunity to observe the impact of the policies on host communities and refugees, where "international organizations have developed and promoted weak policies that do not advocate for the needs of Syrian refugees, and often forget about the challenges faced by Jordanians." Spending more time working with Syrian and Jordanian colleagues, students better understood the challenges of programs and policies implemented by global stakeholders, which are "strongly influenced by the Western mindset. It does not seem that the culture, religion, community and way of life is being considered [...therefore,] many of the policies don't work."

Students found that many local organizations working on the community level are more aligned with the rights and needs of the people they serve, even when they have been founded by foreigners. One student was specifically 
concerned that "the work [of this organization] might feel very 'white-savior-y,' however, what I witnessed was very much the opposite. Although two white women still lead the organization, the coaches and participants are the real leaders of the program." Thus, out of many lessons learned, the overwhelming majority discussed learning the most from the people of diverse backgrounds within the context of practice that reflects different socio-economic, political, and cultural realities. These conditions and practices differed from what students learned at home, which is mostly based on practice within high-resource Western countries. Being immersed in a different reality, students examined their privileges and identities that both defined attitudes toward them and pushed them out of their comfort zone. One of the male students talked about his role during the meetings with Syrian women:

I think there were a few rooms in which the beneficiaries would have been more comfortable and open in their discussion if I, as a male, was not in the room. If I had the chance again, I would have taken the initiative to leave the room and let the conversation flourish.

In summary, the course participants expressed personal and professional growth beyond expectations reflected in their applications. Traveling to Jordan gave many students an opportunity to learn about practice with displaced persons in a region of the world with which they otherwise were unfamiliar. One student described the transformative experience:

As I reflect on this trip, I think I have inclined my interest on Latin America because it's "easy" for me to fit in because I'm comfortable with the language and some cultural aspects that most Hispanic cultures share in common. However, with this experience, I think as a professional who aspires to work in this field, I need to push myself out of my comfort zone and explore different issues. This trip allowed me to do that.

This experience shaped the way students view international social welfare and humanitarian response fields. Students discussed applying a more critical lens to "programming, funding, and the pros and cons of aid work." For some, this trip solidified the desire to work in the field of international social work, whereas others came to question their role in this work and their ability to make a meaningful impact. The opportunity to collaborate with stakeholders and learn from local expertise shaped the way students were thinking about this work: "hearing the professionals' opinions and engaging with local people helped me to navigate my role as a social worker in this field and humanitarian work with refugees." All of the students in the 2020 cohort whose field trip was canceled reflected on the missed opportunity to observe the realities of practice, while also being grateful for the opportunity to learn from their partner agencies throughout the project preparation phase, which they considered to still be superior to the experience of learning only from theory.

\section{Discussion and Conclusion}

This course emerged as a response to increasing student interest in practicing within the field of humanitarian response, as the number of displaced people continued to grow each year. The interconnected world, which makes not only cross-country social work but also domestic practice global, requires that educators prepare all future practitioners for the opportunities and challenges of such reality. Experiential courses that expose students to the realities of international social work practice should be part of the required curricula, just like other standard courses that teach social work skills, building on the assumption that students can apply the theoretical knowledge to their field practice. According to Mapp and Gatenio Gabel (2019), international social work is mostly taught using a range of models from an infusion of the international content into curricula, shortterm study trips, to international field placements. Our analysis of reflections from the three cohorts of students participating in the Social Work Practice with Displaced Persons course suggests that the project-based, experiential model may effectively combine some of the advantages of different models of teaching international social work to provide future social workers with the necessary skills to feel confident and ready to practice in the globalized world. This readiness has never been more critical than during the times of global crisis, such as mass conflict-related, climateinduced displacement, or other disasters and pandemics.

Experiential learning theory suggests that education is more effective when the learner acquires knowledge from their environment and own experiences which can be tested and adjusted according to the changing environment and conditions (Kolb \& Kolb, 2012). In the field of humanitarian response and practice with displaced persons, immersing students in the environment where most of the action takes place is more difficult to accomplish outside the context of the Global South, where the majority of displaced persons are hosted. This course, building on the observations and experiences of the instructors in the field of international social welfare, aimed to provide skills and knowledge to graduate social work professionals so they would be better prepared to practice human rights, social justice, ethically sound, trauma-informed care, and culturally appropriate practices within the field of humanitarian response. Comparison of the qualitative data across the three cohorts of students participating in the course has shown areas of 
personal and professional growth in students, aligned with the goals of the course and students' own expectations reflected in their course applications.

The contextually and structurally diverse experiences provided by the course supported the learning needs of students with different skillsets, backgrounds, and foci. The qualitative data provide examples of deep self-reflection on the issues of positionality and professional practice that is strength-based, anti-oppressive, context appropriate, and human rights and social justice driven, countering the "white savior" and colonial (McGloin \& Georgeou, 2016) practices that are still prevalent in international development. Students' critical analysis of current practices and frameworks of response to the needs of displaced people in global and specific country contexts also shine light on the level of students' understanding of not only the major challenges faced by the displaced population but also their resiliency and strengths. Although not the focus of the analysis in this paper, the final products of the collaborative projects also provide evidence of students' learning. Throughout the process of assessing the needs and strengths of the partner agency, student teams used a careful, culturally sensitive, respectful, and strength-based approach in designing and implementing their projects. Based on the feedback provided by the partner agencies, the overwhelming majority were satisfied by the products that students developed and the approaches that they used.

In comparing the elements of the courses that were most conducive to learning, the immersive nature of the experience (in line with Zubaroglu \& Popescu, 2016), as well as comprehensive overview of the field of practice through exposure to various sectors and stakeholders, was named the most by students. However, the project-based approach, where students partnered with agencies in the field, seemed to be more effective in creating two-way learning that was mutually beneficial for students and agency partners. This reflective and reverse mission framework is critical according to Das and Anand (2014) and Abrams et al. (2005) to challenge the traditional learning methods based on Eurocentrism and neo-Colonialism, which presumes the superiority of knowledge originating from the Global North.

While offering more meaningful engagement and in-depth learning opportunities to students, the project-based partnership offered agencies the time, human, and academic resources to which they might not have easy access. In humanitarian emergencies, agencies rarely have extra time and resources to conduct the needed assessments, evaluation, or research for program planning. As self-reported by agencies, some of the products developed by students have been used in high-stake meetings on agency performance or presented as products of organizations to be replicated in other places. There were also some setbacks in the process, such as when one of the projects was not completed in time and submitted to the agency late due to many logistical challenges the group faced. Besides this one product, to our knowledge, all others (2018-2019 cohorts) have been successfully used to further improve existing programs or to design new programs and policies. COVID-19 also affected the implementation of project activities in 2020. Three out of four scheduled projects were cancelled, while one of the groups was able to complete their project activities remotely.

The value of project-based capstone engagement between the students and the "client agencies" is well-documented in the field of international affairs (Schachter \& Schwartz, 2009; Reinfenberg \& Long, 2017). In social work, although capstone projects may look different, those that have required project engagement, such as research or collaboration with an agency to apply the knowledge students learned to the real issues of practice, may be better positioned to prepare students for real world practice (Apgar, 2019; Peterson et al., 2011). While final conclusions cannot be drawn regarding the outcomes for students taking this course due to absence of deliberate measurements of such outcomes, the qualitative and course satisfaction data can indicate a positive impact. Additionally, the intersectional design of the course inviting social work students from various fields of practice (clinical, policy, social enterprise, generalist practice) was another successful element that contributed to a more holistic approach to the process of co-learning.

Thus, experiential project-based learning has great potential for modeling internationally focused social work courses that provide opportunity to not only learn about various areas of practice and skills, but also a chance for students to better understand context of practice through an anti-oppressive, human rights, culturally relevant lens. Further research should focus on measuring the impact of such courses on student's learning outcomes, as well as partner agency perceptions of the benefit of such engagement.

\section{References}

Abram, F. Y., Slosar, J. A., \& Walls, R. (2005). Reverse mission: A model for international social work education and transformative intra-national practice. International Social Work, 48(2), 161176. https://doi.org/10.1177/0020872805050490

Ahmadi, N. (2003). Globalization of consciousness and new challenges for international social work. International Journal of Social Welfare, 12(1). https://doi.org/10.1111/1468-2397.00005

Apgar, D. (2019). Conceptualization of capstone experiences: Examining their role in social work education. Social Work Education 38 (2). https://doi.org/10.1080/02615479.2018.15129632018.1512963

Boyle, D. P., Nackerud, L., \& Kilpatrick, A. (1999). The road less traveled: Cross-cultural, international experiential learning. International Social Work, 42(2), 201-214. https://doi.org/10. $1177 / 002087289904200208$ 
Brown, C. L. (2017). Linking public health nursing competencies and service-learning in a global setting. Public Health Nursing, 34(5), 485-492.

Caragata, L., \& Sanchez, M. (2002). Globalization and global need: New imperatives for expanding international social work education in North America. International Social Work, 45(2), 217-238. https://doi.org/10.1177/00208728020450020201

CSWE. (2015). 2015 Educational policy and accreditation standards for baccalaureate and master's social work programs. Retrieved from https://cswe.org/getattachment/Accreditation/Standards-andPolicies/2015-EPAS/2015EPASandGlossary.pdf.aspx

Cole, T. (2012). The White-Savior Industrial Complex. The Atlantic. Retrieved from https://www.theatlantic.com/international/archive/ 2012/03/the-white-savior-industrial-complex/254843/

Danford, G. L. (2004). Project-based learning and international business education. Journal of Teaching in International Business., 18(1), 7-25. https://doi.org/10.1300/J066v18n01_02

Das, C., \& Anand, J. C. (2014). Strategies for critical reflection in international contexts for social work students. International Social Work, 57(2), 109-120. https://doi.org/10.1177/0020872812443693

Dominelli, L. (2014). Internationalizing professional practices: The place of social work in the international arena. International Social Work, 57(3), 258-267. https://doi.org/10.1177/0020872814522671

Estes, R. J. (2010). United States-based conceptualization of international social work education. Retrieved from https://repository.upenn.edu/ spp_papers/181

Fortune, T., Borkovic, S., Bhopti, A., Somoza, R., Nhan, H. C., \& Rangwala, S. (2019). Transformative learning through international project-based learning in the global south: Applying a students-as-partners lens to a "high-impact" capstone. Journal of Studies in International Education, 23(1), 49-65. https://doi. org/10.1177/1028315318814571

Greenfield, E. A, Davis, R. T., \& Fedor, J. P. (2012). The effect of international social work education: Study abroad versus on-campus courses. Journal of Social Work Education, 48(4), 739-761.

Healy, L. M. (2008). International social work: Professional action in an interdependent world. New York, NY: Oxford University Press.

Kjørstad, M., \& Wolmesjö, M. (2016). Becoming aware of the grand social challenges: How an international and interdisciplinary educational context may broaden students' perspectives on human rights and public health. European Journal of Social Work, 20(1), 125-138. https://doi.org/10.1080/13691457.2016

Kolb, A. Y., \& Kolb, D. A. (2012). Experiential learning theory. In Encyclopedia of the Sciences of Learning [Online]. https://doi. org/10.1007/978-1-4419-1428-6_227
Lough, B. J. (2014). Social work perspectives on international volunteer service. British Journal of Social Work, 44, 1340-1355.

Mapp, S. C., \& Gatenio Gabel, S. (2019). Educating students on international social work issues in U.S. social work programs: How is it done? Journal of Social Work Education, 55(2), 238250. https://doi.org/10.1080/10437797.2018.1513882018.151388

Mapp, S. C., \& Rice, K. (2018). Conducting rights-based shortterm study abroad experiences. Social Work Education: The International Journal, 38(4), 427-438. https://doi. org/10.1080/02615479.2018.1560403

McGloin, C. \& Georgeou, N. (2016). 'Looks good on your CV': The sociology of voluntourism recruitment in higher education. Journal of Sociology 52(2).

Mercer-Mapstone, L., Dvorakova, S. L., Matthews, K., Abbot, S., Cheng, B., Felten, P., Knorr, K., Marquis, E., Shammas, R., \& Swaim, K. (2017). A systematic literature review of students as partners in higher education. International Journal for Students As Partners, 1(1). https://doi.org/10.15173/ijsap.v1i1.3119

Moorhead, M., Boetto, H., \& Bell, K. (2013). India and US: Student development of professional social work identity through a shortterm study abroad program. Social Work Education, 33(2), 175189. https://doi.org/10.1080/02615479.2013.768614

Peterson, S.M., Phillips, A., Bacon, S.I \& Machunda Z. (2011). Teaching evidence-based practice at the BSW level: An effective capstone project. Journal of Social Work Education, 47(3).

Reifenberg, S., \& Long, S. (2017). Negotiating the client-based capstone experience. International Journal of Teaching and Learning in Higher Education, 29(3), 580-588.

Schachter, D. R., \& Schwartz, D. (2009). The value of capstone projects to participating client agencies. Journal of Public Affairs Education, 15(4), 445-462. https://doi.org/10.1080/15236803.2009.12001571

Sewpaul, V. \& Jones, D. (2005). Global standards for education and training of the social work profession. International Journal of Social Welfare, 14(3).

UNHCR (2021). Figures at a glance. Resource document. UNHCR, The UN Refugee Agency. https://www.unhcr.org/en-us/figures-ata-glance.html

Zubaroglu, P. \& Popescu, M. (2016). Preparing social work students for international interdisciplinary practice: A teaching model and its impact on self-efficacy. Advances in Social Work, 16(2). https:// doi.org/10.18060/18504

Publisher's Note Springer Nature remains neutral with regard to jurisdictional claims in published maps and institutional affiliations. 